\title{
Structural Analysis of Two Trisaccharides Isolated from Fermented Beverage of Plant Extract
}

\author{
Naoki Kawazoe ${ }^{\mathrm{a}, \mathrm{c}}$, Hideki Okada ${ }^{\mathrm{a}}$, Eri Fukushi ${ }^{\mathrm{b}}$, Akira Yamamori ${ }^{\mathrm{a}}$, Shuichi Onodera ${ }^{\mathrm{c}}$, Jun Kawa- \\ bata $^{\mathrm{b}}$ and Norio Shiomi*,c \\ ${ }^{a}$ Ohtakakohso, Co., Ltd., Otaru 047-0193, Japan \\ ${ }^{b}$ Graduate School of Agriculture, Hokkaido University, Sapporo 060-8589, Japan \\ ${ }^{c}$ Department of Food and Nutrition Sciences, Graduate School of Dairy Science Research, Rakuno Gakuen University, \\ Ebetsu 069-8501, Japan
}

\begin{abstract}
Fermented beverage of plant extract was prepared from about fifty kinds of vegetables and fruits. Natural fermentation was carried out mainly by lactic acid bacteria (Leuconostoc spp.) and yeast (Zygosaccharomyces spp.and Pichia spp.). Two novel oligosaccharides have been found from this beverage and isolated from the beverage using carbon-Celite column chromatography and preparative high performance liquid chromatography. Structure confirmation of the saccharides was provided by methylation analysis, MALDI-TOF-MS and NMR measurements. These saccharides were identified as new trisaccharides, $\beta$-D-glucopyranosyl-( $1 \rightarrow 1)$ - $\beta$-D-fructofuranosyl- $(2 \leftrightarrow 1)$ - $\alpha$-D-glucopyranoside; $\beta$-Dgalactopyranosyl- $(1 \rightarrow 1)-\beta$-D-fructofuranosyl- $(2 \leftrightarrow 1)-\alpha$-D-glucopyranoside.
\end{abstract}

Keywords: $1^{\mathrm{F}}$ - $\beta$ - D-galactosylsucrose, $1^{\mathrm{F}}-\beta$ - D-glucosylsucrose, Fermented beverage of plant extract, Trisaccharide.

\section{INTRODUCTION}

The extract from 50 kinds of fruits and vegetables was fermented to produce a new beverage $[1,2]$. The juices were extracted using sucrose-osmotic pressure in cedar barrels for one week and were fermented by lactic acid bacteria (Leuconostoc spp.) and yeast (Zygosaccharomyces spp. and Pichia spp.).

We have already studied isolation and identification of novel saccharides, such as $\beta$-D-fructopyranosyl-( $2 \rightarrow 6)$-Dglucopyranose[2], $\beta$-D-fructopyranosyl-( $2 \rightarrow 6)-\beta$-D-glucopyranosyl-( $1 \rightarrow 3)$-D-glucopyranose and $\beta$-D-fructopyranosyl$(2 \rightarrow 6)$-[ $\beta$-D-glucopyranosyl- $(1 \rightarrow 3)]$-D-glucopyranose [3] from fermented beverage of plant extract. The characteristics of $\beta$-D-fructopyranosyl-( $2 \rightarrow 6)$-D-glucopyranose were noncariogenicity, low digestibility and the unfavorable bacteria, Clostridium perfringens, Escherichia coli and Enterococcus faecalis that produce mutagenic substances and did not use the saccharide. Furthermore, those novel saccharides were confirmed to be produced by fermentation.

In this paper, we confirmed structures of novel trisaccharides; $\quad \beta$-D-glucopyranosyl-( $1 \rightarrow 1)-\beta$-D-fructofuranosyl-(2 $\leftrightarrow 1)-\alpha$-D-glucopyranoside $\quad\left[1^{\mathrm{F}}-\beta\right.$-D-glucopyranosylsucrose $]$ and $\quad \beta$-D-galactopyranosyl- $(1 \rightarrow 1)-\beta$-D-fructofuranosyl- $(2$ $\leftrightarrow 1)$ - $\alpha$-D-glucopyranoside $\quad\left[1^{\mathrm{F}}-\beta\right.$-D-galactopyranosylsucrose] (Fig. 1) isolated from the fermented beverage using methylation analysis, MALDI-TOF-MS and NMR measurements.

*Address correspondence to this author at the Department of Food and Nutrition Sciences, Graduate School of Dairy Science Research, Rakuno Gakuen University, Ebetsu 069-8501, Japan;

E-mail: n-shiomi@rakuno.ac.jp

\section{MATERIALS AND METHODS}

\section{Materials}

$p$-Aminobenzoic acid ethyl ester (ABEE) labeling kit was purchased from Seikagaku Kogyo Corporation (Tokyo, Japan). Sucrose, glucose, fructose and galactose were purchased from Sigma Chemical Co. (St. Louis, MO, USA).

\section{p-Aminobenzoic Acid Ethyl Ester (ABEE) Conversion Method}

The $p$-aminobenzoic acid ethyl ester (ABEE)-conversion method is a simple and highly sensitive precolumn method for the analysis of oligosaccharides. Carbohydrates are coupled with ABEE at the reducing end by reductive amination. Conversion of the saccharides at the reducing end with ABEE was carried out according to the method of Yasuno et al. $[4,5]$. Ten $\mu \mathrm{L}$ of standard saccharide solution was added to an ABEE reagent solution $(40 \mu \mathrm{L})$. The mixture was incubated at $80^{\circ} \mathrm{C}$ for $1 \mathrm{~h}$. Distilled water $(0.2 \mathrm{~mL})$ and chloroform $(0.2 \mathrm{~mL})$ were added and mixture was centrifuged at $10,000 \mathrm{rpm}$ for $1 \mathrm{~min}$, aqueous layer was diluted 100 -fold with water and subjected to HPLC analysis. Analytical conditions are as follows: mobile phase, $0.1 \mathrm{M}$ ammonium acetate buffer ( $\mathrm{pH} 4.0$ ) containing $10.5 \%$ acetonitrile; flow rate, $0.5 \mathrm{~mL} / \mathrm{min}$; column temperature, room temp; and detected by $\mathrm{UV}$ at $305 \mathrm{~nm}$.

\section{High Performance Anion-Exchange Chromatography (HPAEC)}

The oligosaccharides were analyzed using a Dionex Bio LC Series apparatus equipped with an HPLC carbohydrate column (Carbo Pack PA1, inert styrene divinyl benzene polymer) and pulsed amperometric detection (PAD) $[6,7]$ The mobile phase consisted of eluent A $(150 \mathrm{mM} \mathrm{NaOH})$ 
and eluent $\mathrm{B}$ (500 $\mathrm{mM}$ sodium acetate in $150 \mathrm{mM} \mathrm{NaOH}$ ) with a sodium acetate gradient as follows: 0-1 min, $25 \mathrm{mM}$; 1-2 min, 25-50 mM; 2-20 min, 50-200 mM; 20-22 min, 500 $\mathrm{mM}$; 22-30 $\mathrm{min}, 25 \mathrm{mM}$; using a flow rate of $1.0 \mathrm{~mL} / \mathrm{min}$. The applied PAD potentials for E1 $(500 \mathrm{~ms})$, E2 (100 ms), and $\mathrm{E} 3(50 \mathrm{~ms})$ were $0.1,0.6$, and $-0.6 \mathrm{~V},[8,9]$ respectively, and the output range was $1 \mu \mathrm{C}$.
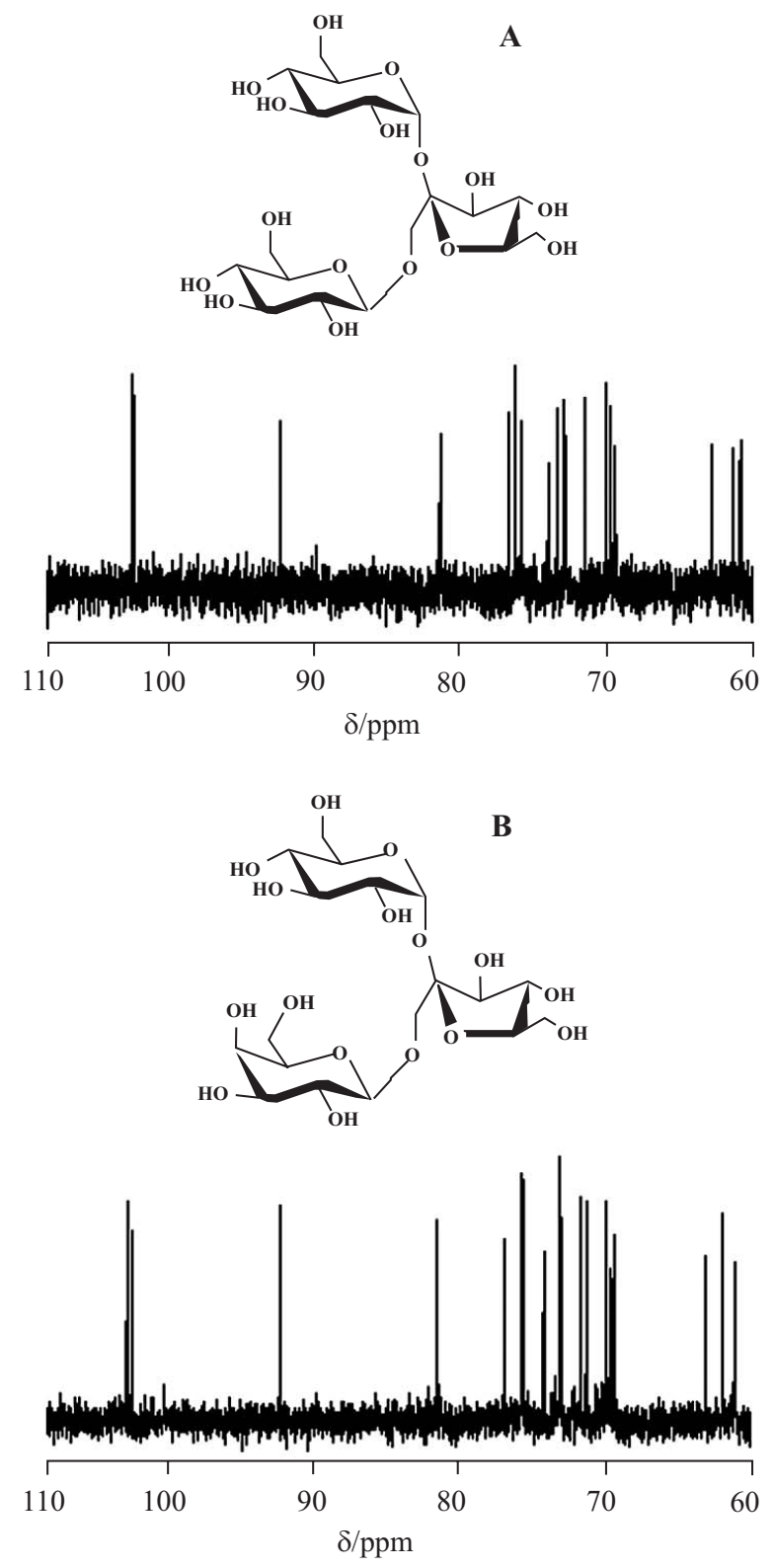

Fig. (1). Structures and ${ }^{13} \mathrm{C}$ NMR spectra of $\beta$-D-glucopyranosyl$(1 \rightarrow 1)$ - $\beta$-D-fructofuranosyl- $(2 \leftrightarrow 1)-\alpha$-D-glucopyranoside $(\mathbf{A})$ and $\beta$ D-galactopyranosyl-( $1 \rightarrow 1)-\beta$-D-fructofuranosyl-( $2 \leftrightarrow 1)-\alpha-D-$ glucopyranoside (B).

\section{Isolation of Saccharides}

Preparation of fermented beverage of plant extract was described in a previous paper [1, 2]. Fermented beverage of plant extract $(1.0 \mathrm{~kg})$ was loaded onto to a carbon-Celite [1:1; charcoal (Wako Pure Chemical Industries, Ltd., Osaka, Japan) and Celite-535 (Nacalai Chemical Industries, Ltd.,
Osaka, Japan)] column $(4.5 \times 35 \mathrm{~cm})$ and successively eluted with water $(14 \mathrm{~L}), 5 \%$ ethanol $(26 \mathrm{~L})$ and $30 \%$ ethanol (30L). Almost all of glucose and fructose were eluted with water (4L) and then saccharides $\mathbf{1}$ and $\mathbf{2}$ were eluted with $30 \%$ ethanol (1-2L). Saccharides 1 and $\mathbf{2}$ fraction was concentrated in vacuo and freeze-dried to give $894 \mathrm{mg}$. Subsequently, 30\% ethanol fraction was successfully purified repeatedly using a HPLC system (Tosoh, Tokyo, Japan) equipped with an Amide- 80 column $(7.8 \mathrm{~mm} \times 30 \mathrm{~cm}$, Tosoh, Tokyo, Japan) at $80^{\circ} \mathrm{C}$, and eluted with $80 \%$ acetonitrile at $2.0 \mathrm{~mL} / \mathrm{min}$, and using refractive index detection. Furthermore, the saccharides were purified by HPLC system with the ODS-100V column $(4.6 \mathrm{~mm} \times 25 \mathrm{~cm}$, Tosoh, Tokyo, Japan) at room temperature, and eluted with water at $0.5 \mathrm{~mL} / \mathrm{min}$. Purified saccharides $1(3.5 \mathrm{mg})$ and $2(2.0 \mathrm{mg})$ were obtained as white powders.

\section{Methylation and Methanolysis}

Methylation of the oligosaccharides was carried out by the method of Hakomori [10].

The permethylated saccharides were methanolysed by heating with $1.5 \%$ methanolic hydrochloric acid at $96^{\circ} \mathrm{C}$ for 10 or $180 \mathrm{~min}$. The reaction mixture was treated with Amberlite IRA-410 $\left(\mathrm{OH}^{-}\right)$to remove hydrochloric acid, and evaporated in vacuo to dryness. The resulting methanolysate was dissolved in a small volume of methanol and analyzed using gas chromatography.

\section{Gas Liquid Chromatography (GC)}

For the analysis of the methanolysate, GC was carried out using a Shimadzu GC8A gas chromatograph equipped with a glass column $(2.6 \mathrm{~mm} \times 2 \mathrm{~m})$ packed with $15 \%$ butane 1,4-diol succinate polyester on acid-washed Celite at $175^{\circ} \mathrm{C}$. Flow rate of the nitrogen gas carrier was $40 \mathrm{~mL} / \mathrm{min}$.

\section{Matrix Assisted Laser Desorption Ionization Time of Flight Mass Spectrometry (MALDI-TOF-MS)}

MALDI-TOF-MS spectra were obtained on a ShimadzuKratos mass spectrometer (KOMPACT Probe) using 2, 5dihydroxybenzoic acid matrix.

\section{NMR Measurements}

The saccharide (ca. $3.0 \mathrm{mg}$ of $\mathbf{1}$ and $1.0 \mathrm{mg}$ of 2) was dissolved in $0.4 \mathrm{~mL} \mathrm{D}_{2} \mathrm{O}$. NMR spectra were recorded at

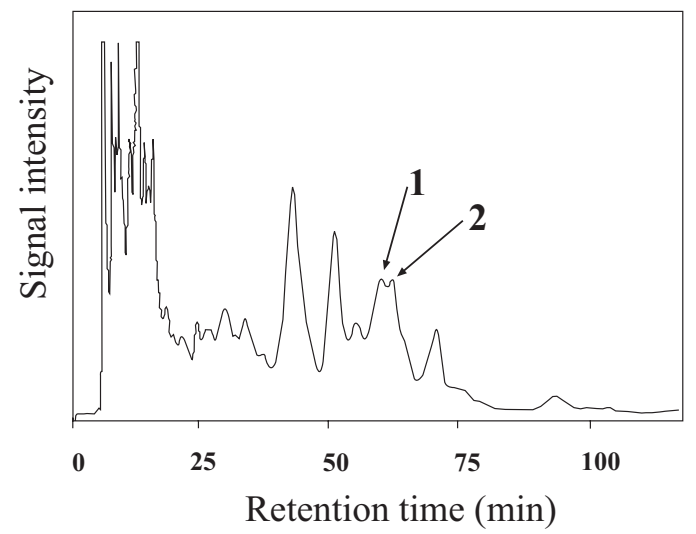

Fig. (2). Preparative HPLC of saccharides 1 and $\mathbf{2}$ fraction separated from fermented beverage by carbon-Celite column chromatography. Isolation of saccharides was done by normal phase HPLC using amide- 80 column. 
Table 1. Gas-Liquid Chromatographic Analysis of Methanolysates of Permethylated Saccharide 1 and 2

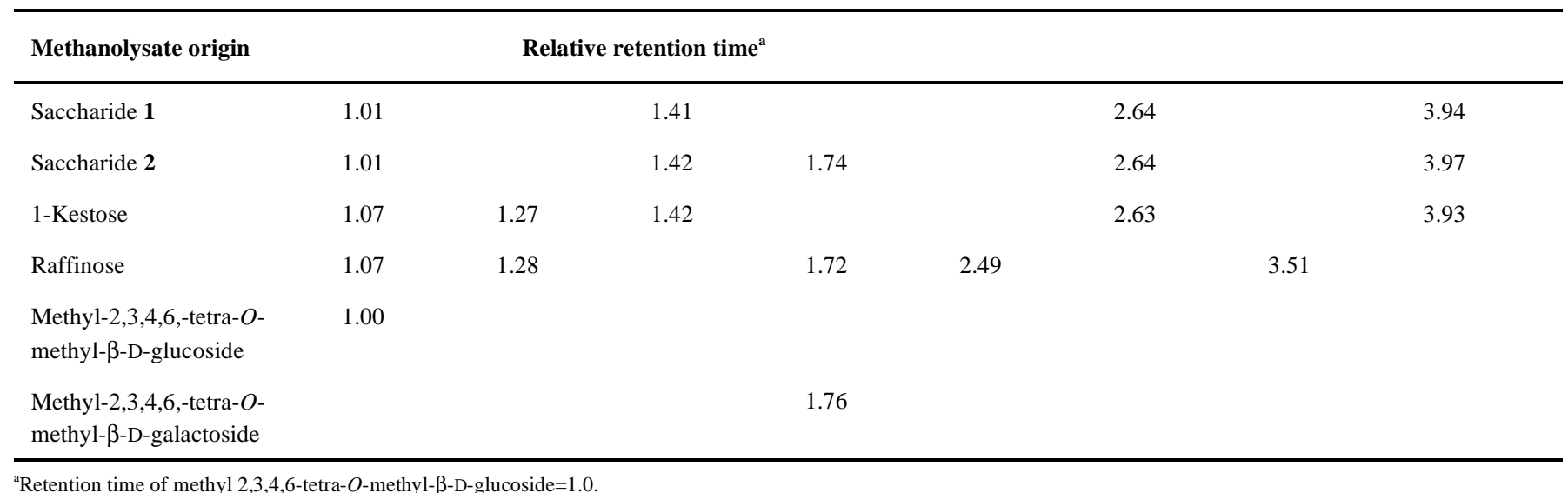

$27^{\circ} \mathrm{C}$ with a Bruker AMX 500 spectrometer $\left({ }^{1} \mathrm{H} 500 \mathrm{MHz}\right.$, ${ }^{13} \mathrm{C} 125 \mathrm{MHz}$ ) equipped with a $5 \mathrm{~mm}$ diameter $\mathrm{C} / \mathrm{H}$ dual (1D spectra) and TXI prove (2D spectra). Chemical shifts of ${ }^{1} \mathrm{H}$ $\left(\delta_{\mathrm{H}}\right)$ and ${ }^{13} \mathrm{C}\left(\delta_{\mathrm{C}}\right)$ in $\mathrm{ppm}$ were determined relatively to the external standard of sodium $\left[2,2,3,3{ }^{2} \mathrm{H}_{4}\right]-3$-(trimethylsilyl) propanoate in $\mathrm{D}_{2} \mathrm{O}\left(\delta_{\mathrm{H}} 0.00 \mathrm{ppm}\right)$ and 1, 4-dioxane $\left(\delta_{\mathrm{C}} 67.40\right.$ ppm) in $\mathrm{D}_{2} \mathrm{O}$, respectively. ${ }^{1} \mathrm{H}-{ }^{1} \mathrm{H}$ COSY, $[11,12] \mathrm{HSQC}$ [13], and $\mathrm{HMBC}[14,15]$ spectra were obtained using gradient selected pulse sequences. The phase sensitive HSQCTOCSY spectra were determined with the sequence including inversion of direct resonance (IDR) [16]. The TOCSY mixing time $(83 \mathrm{~ms})$ was composed of DIPSI-2 composite pulses.

\section{RESULTS AND DISCUSSION}

Isolation of saccharides from fermented beverage of plant extract was performed by carbon-Celite column chromatography and preparative HPLC (Fig. 2). These saccharides were shown to be homogeneous using anion exchange HPLC $\left(\mathrm{t}_{\mathrm{R}, \text { sucrose }}\right.$ (relative retention time; retention time of sucrose $=1.0): 1.24$ and 0.84).

The retention times of saccharides $\mathbf{1}$ and $\mathbf{2}$ did not correspond to those of any authentic saccharides.

The degrees of polymerization of saccharides $\mathbf{1}$ and $\mathbf{2}$ were established as 3 by measurements of $[\mathrm{M}+\mathrm{Na}]^{+}$ions $(\mathrm{m} / \mathrm{z}: 527)$ using TOF-MS, and analysis of the molar ratios of D-glucose, D-galactose and D-fructose in the acid hydrolysates of the oligosaccharides using ABEE-conversion method. Partial acid hydrolysate of saccharide 1 was liberated to glucose, fructose and sucrose, and saccharide 2 was liberated to galactose, glucose, fructose and sucrose.

From the GC analysis, relative retention times of the methanolysate of the permethylated saccharides were investigated [ $\mathrm{t}_{\mathrm{R}}$ (relative retention time; retention time of methyl $2,3,4$, 6-tetra- $O$-methyl- $\beta$-D-glucoside $=1.0$; retention time, $9.60 \mathrm{~min})]$. The methanolysate of permethylated saccharide 1 exhibited four peaks (Table 1) corresponding to methyl 2,3,4,6-tetra- $O$-methyl-D-glucoside $\left(\mathrm{t}_{\mathrm{R}}, 1.01\right.$ and 1.41$)$ and methyl 3,4,6- tri- $O$-methyl-D-fructoside ( $\mathrm{t}_{\mathrm{R}}, 2.64$ and 3.94).

The methanolysate of permethylated saccharide 2 also exhibited five peaks (Table 1) corresponding to methyl 2,3,4,6-tetra- $O$-methyl-D-glucoside $\left(\mathrm{t}_{\mathrm{R}}, \quad 1.01\right.$ and 1.42$)$, methyl 2,3,4,6-tetra- $O$-methyl-D-galactoside $\left(\mathrm{t}_{\mathrm{R}}, 1.74\right)$, and methyl 3,4,6-tri- $O$-methyl-D-fructoside ( $\mathrm{t}_{\mathrm{R}}, 2.64$ and 3.97).

From these findings as above, saccharides 1 and $\mathbf{2}$ were proved to be D-glucosyl-(1 $\rightarrow 1)$-D-fructosyl-( $2 \leftrightarrow 1)$-Dglucoside and D-galactosyl-( $1 \rightarrow 1)$-D-fructosyl-( $2 \leftrightarrow 1)$-Dglucoside, respectively.

Next, the NMR spectra of saccharide 1 were analyzed. The HSQC-TOCSY spectrum revealed the ${ }^{1} \mathrm{H}$ and ${ }^{13} \mathrm{C}$ signals of each Glc, Glc' and Fru. The isolated methylene was assigned as $\mathrm{H}-1$ and $\mathrm{C}-1$ in Fru. The other three methylene carbons were assigned as C-6 in these residues. The COSY spectrum assigned the spin systems of these residues; from $\mathrm{H}-1$ to $\mathrm{H}-5$ in each Glc,

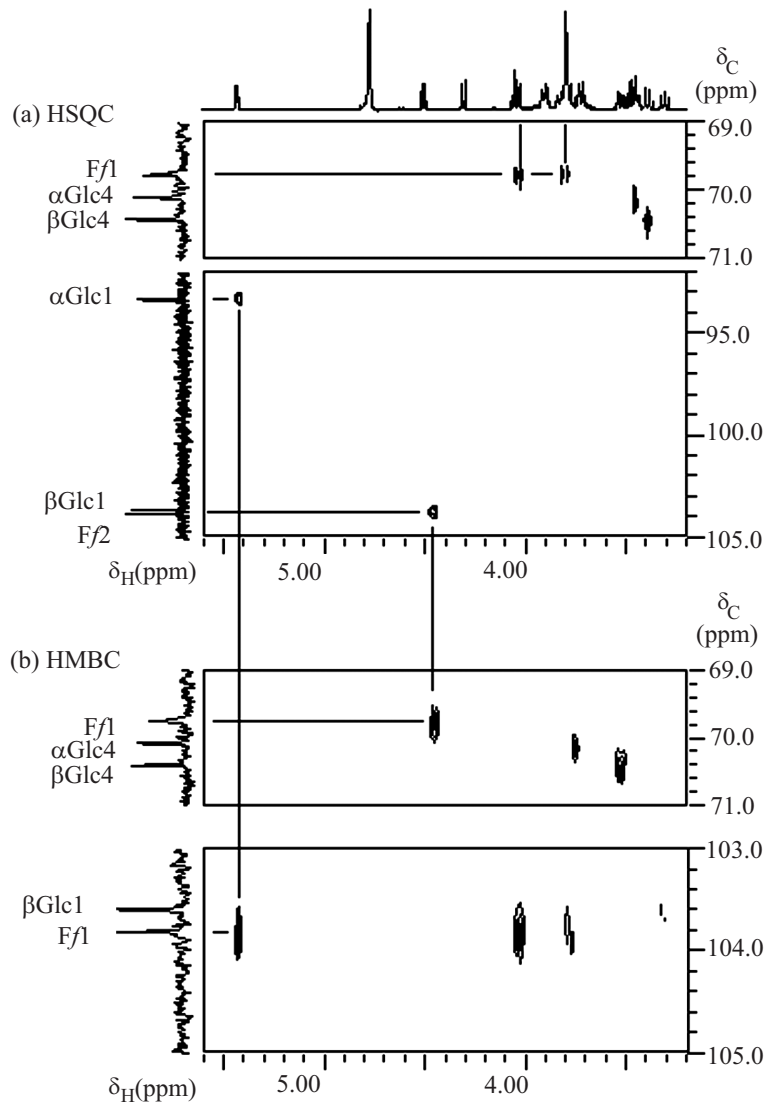

Fig. (3). Part of HSQC (a) and HMBC (b) spectra of saccharide 1. 
Glc', and from H-3 to H-6 in Fru. The corresponding ${ }^{13} \mathrm{C}$ signals were assigned by HSQC spectrum. The HMBC correlation of $\mathrm{C}-1 / \mathrm{H}-3$ in Fru could assign this carbon. These results clarified the assignment of ${ }^{1} \mathrm{H}$ and ${ }^{13} \mathrm{C}$ NMR signals of each residue.

The position of glucosidic linkage was analyzed as follows. The C-2 in Fru showed the HMBC correlations between $\mathrm{H}-1$ in Glc (Fig. 3 (a) and (b)). The $J(\mathrm{H}-1 / \mathrm{H}-2)$ value in Glc was $3.9 \mathrm{~Hz}$.

These results indicated the Glc $1 \alpha \leftrightarrow 2$ Fru linkage, namely, the sucrose moiety. The C-1 of Fru showed the
HMBC correlations to $\mathrm{H}-1$ of Glc'. The $J(\mathrm{H}-1 / \mathrm{H}-2)$ value in Glc' was $8.0 \mathrm{~Hz}$. These results indicated the Glc $1 \beta \rightarrow 1 \mathrm{Fru}$ linkage, and all ${ }^{1} \mathrm{H}$ and ${ }^{13} \mathrm{C}$ NMR signals were assigned as shown in Table 2 . The coupling patterns of overlapped ${ }^{1} \mathrm{H}$ were analyzed by SPT method [18, 19]. Due to strong coupling between H-6 methylene protons in Glc and between $\mathrm{H}-$ 6 methylene protons in Fru, these couplings could not be analyzed in first order.

The NMR spectra of saccharide 2 were analyzed in the same manner of those of saccharide 1. Galactosyl residue and glucosyl residue were assigned by ${ }^{1} \mathrm{H}-{ }^{1} \mathrm{H}$ COSY and $J_{\mathrm{HH}}$. HSQC-TOCSY spectrum revealed the ${ }^{1} \mathrm{H}$ and ${ }^{13} \mathrm{C}$ signals of

Table 2. ${ }^{1} \mathrm{H}$ and ${ }^{13} \mathrm{C}$ NMR Spectral Data $\left(\delta^{\mathrm{a}}\right.$ in ppm, $J$ in Hz) of Saccharides 1 and 2

\begin{tabular}{|c|c|c|c|c|c|c|c|c|c|}
\hline & & \multicolumn{3}{|c|}{ Saccharide 1} & \multicolumn{5}{|c|}{ Saccharide 2} \\
\hline & & $\delta_{\mathrm{C}}$ & $\delta_{\mathrm{H}}$ & & $J_{\mathrm{HH}}$ & $\delta_{\mathrm{C}}$ & $\delta_{\mathrm{H}}$ & & $J_{\mathrm{HH}}$ \\
\hline \multirow[t]{6}{*}{$\alpha \mathrm{Glc}$} & 1 & 93.32 & 5.43 & $\mathrm{~d}$ & 3.9 & 93.36 & 5.44 & $\mathrm{dd}$ & 3.9 \\
\hline & 2 & 71.96 & 3.54 & $\mathrm{dd}$ & $10.5,3.9$ & 71.99 & 3.55 & $\mathrm{dd}$ & $10.1,3.9$ \\
\hline & 3 & 73.44 & 3.74 & $\mathrm{dd}$ & $10.5,9.2$ & 73.45 & 3.75 & $\mathrm{dd}$ & $10.1,9.3$ \\
\hline & 4 & 70.09 & 3.46 & $\mathrm{dd}$ & $10.0,9.2$ & 70.11 & 3.47 & $\mathrm{dd}$ & $9.9,9.3$ \\
\hline & 5 & 73.27 & 3.84 & ddd & $10.0,3.7,2.7$ & 73.29 & 3.85 & ddd & $9.9,3.5,3.0$ \\
\hline & 6 & 60.98 & 3.81 & $\mathrm{~m}$ & & 60.99 & 3.81 & $\mathrm{~m}$ & \\
\hline \multirow[t]{7}{*}{ Fruf } & 1 & 69.76 & 4.05 & $\mathrm{~d}$ & 11.1 & 69.81 & 4.07 & $\mathrm{~d}$ & 11.2 \\
\hline & & & 3.80 & $\mathrm{~d}$ & 11.1 & & 3.80 & d & 11.2 \\
\hline & 2 & 103.82 & & & & 104.19 & & & \\
\hline & 3 & 77.29 & 4.31 & $\mathrm{~d}$ & 8.5 & 77.43 & 4.33 & d & 8.9 \\
\hline & 4 & 74.53 & 4.06 & $\mathrm{dd}$ & $8.9,8.5$ & 74.56 & 4.06 & $\mathrm{dd}$ & $8.9,8.4$ \\
\hline & 5 & 82.14 & 3.91 & $\mathrm{~m}$ & $8.9,6.4,4.2$ & 82.13 & 3.92 & ddd & $8.4,6.4,2.7$ \\
\hline & 6 & 63.02 & 3.81 & $\mathrm{~m}$ & & 63.03 & 3.81 & $\mathrm{~m}$ & \\
\hline \multirow[t]{7}{*}{$\beta \mathrm{Gal}$} & 1 & & & & & 104.19 & 4.44 & d & 7.9 \\
\hline & 2 & & & & & 71.57 & 3.56 & $\mathrm{dd}$ & $9.6,7.9$ \\
\hline & 3 & & & & & 73.48 & 3.66 & $\mathrm{dd}$ & $9.6,3.4$ \\
\hline & 4 & & & & & 69.50 & 3.93 & $\mathrm{dd}$ & 3.4 \\
\hline & 5 & & & & & 76.10 & 3.70 & $\mathrm{dd}$ & $8.4,4.6$ \\
\hline & 6 & & & & & 61.85 & 3.80 & $\mathrm{dd}$ & $12.1,8.4$ \\
\hline & & & & & & & 3.78 & $\mathrm{dd}$ & $12.1,4.6$ \\
\hline \multirow[t]{7}{*}{$\beta$ Glc } & 1 & 103.60 & 4.51 & $\mathrm{~d}$ & 8.0 & & & & \\
\hline & 2 & 73.88 & 3.32 & $\mathrm{dd}$ & $9.2,8.0$ & & & & \\
\hline & 3 & 76.44 & 3.50 & $\mathrm{dd}$ & $9.2,9.2$ & & & & \\
\hline & 4 & 70.42 & 3.40 & $\mathrm{dd}$ & $9.8,9.2$ & & & & \\
\hline & 5 & 76.82 & 3.45 & ddd & $9.8,5.7,2.0$ & & & & \\
\hline & 6 & 61.52 & 3.91 & $\mathrm{dd}$ & $12.4,2.0$ & & & & \\
\hline & & & 3.73 & $\mathrm{dd}$ & $12.4,5.7$ & & & & \\
\hline
\end{tabular}

${ }^{\mathrm{a}}$ Chemical shifts of ${ }^{1} \mathrm{H}\left(\delta_{\mathrm{H}}\right)$ and ${ }^{13} \mathrm{C}\left(\delta_{\mathrm{C}}\right)$ in ppm were determined relatively to the external standard of sodium $\left[2,2,3,3-{ }^{2} \mathrm{H}_{4}\right]-3-($ trimethylsilyl $)$ propanoate in $\mathrm{D}_{2} \mathrm{O}\left(\delta_{\mathrm{H}} 0.00\right.$ ppm $)$ and 1,4-dioxane $\left(\delta_{\mathrm{c}} 67.40 \mathrm{ppm}\right)$ in $\mathrm{D}_{2} \mathrm{O}$, respectively. 
each Glc, Gal and Fru. The isolated methylene was assigned as $\mathrm{H}-1$ and $\mathrm{C}-1$ in Fru. The other three methylene carbons were assigned as C-6 in these residues. The COSY spectrum assigned the spin systems of these residues; from $\mathrm{H}-1$ to $\mathrm{H}-5$ in each Glc, Gal, and from H-3 to H-6 in Fru. The corresponding ${ }^{13} \mathrm{C}$ signals were assigned by HSQC spectrum. The HMBC correlation of $\mathrm{C}-3 / \mathrm{H}-1$ in Fru could assign this carbon.

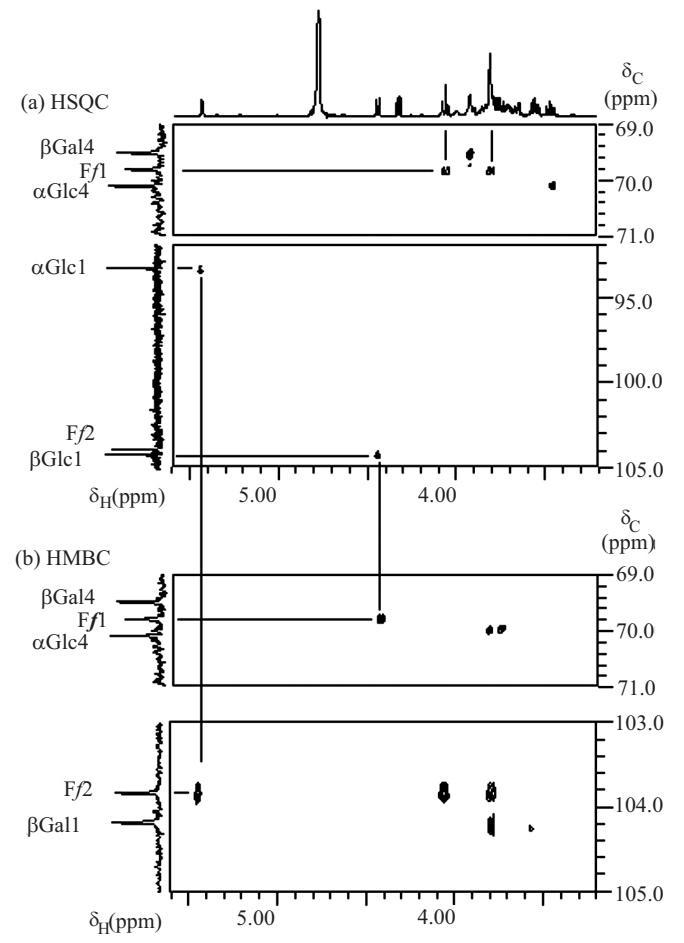

Fig. (4). Part of HSQC (a) and HMBC (b) spectra of saccharide 2.

These results clarified the assignment of ${ }^{1} \mathrm{H}$ and ${ }^{13} \mathrm{C}$ NMR signals of each residue. The position of glycosidic linkage, galactoside linkage, and Fru was analyzed as follows. The C-2 in Fru showed the HMBC correlations between $\mathrm{H}-1$ in Glc (Fig. 4(a) and (b)). The $J(\mathrm{H}-1 / \mathrm{H}-2)$ value in Glc was $3.9 \mathrm{~Hz}$. These results indicated the Glc $1 \alpha \leftrightarrow 2 \mathrm{Fru}$ linkage, namely, the sucrose moiety. The C-1 of Fru showed the HMBC correlations to $\mathrm{H}-1$ of Gal. The $J(\mathrm{H}-1 / \mathrm{H}-2)$ value in $\mathrm{Gal}$ was $7.9 \mathrm{~Hz}$.

These results indicated the Gal $1 \beta \rightarrow 1$ Fru linkage, and all ${ }^{1} \mathrm{H}$ and ${ }^{13} \mathrm{C}$ NMR signals were assigned as shown in Table 2. The coupling patterns of overlapped ${ }^{1} \mathrm{H}$ were analyzed by SPT method. Due to strong coupling between H-6 methylene protons in Glc and between H-6 methylene protons in Fru, these couplings could not be analyzed in first order.

From all of the findings, saccharides $\mathbf{1}$ and $\mathbf{2}$ were identified as $\beta$-D-glucopyranosyl-( $1 \rightarrow 1)-\beta$-D-fructofuranosyl$(2 \leftrightarrow 1)$ - $\alpha$-D-glucopyranoside and $\beta$-D-galactopyranosyl$(1 \rightarrow 1)$ - $\beta$-D-fructofuranosyl-( $2 \leftrightarrow 1)$ - $\alpha$-D-glucopyranoside .

The presence of such as melezitose, $1^{\mathrm{F}}$ - $\alpha$-galactosylsucrose and $6^{\mathrm{F}}-\beta$-galactosylsucrose, has already been reported by Courtois et al. [19] and Pazur et al. [20]. However, saccharides 1 and $\mathbf{2}$ were not found in natural resources excepting the saccharide of the fermented beverage of plant extract.
Synthesis of saccharides $\mathbf{1}$ and $\mathbf{2}$ by fermentation of plant extract was investigated by using HPAEC and these saccharides were produced during fermentation (Fig. 5).

\section{CONCLUSIONS}

Two novel oligosaccharides have been found from this beverage and isolated from the beverage using carbon-Celite column chromatography and preparative high performance liquid chromatography. Structure confirmation of the saccharides was provided by methylation analysis, MALDI-TOFMS and NMR measurements. These the saccharides were identified as new trisaccharides, $\beta$-D-glucopyranosyl-( $1 \rightarrow 1)$ $\beta$-D-fructofuranosyl-(2↔1)- $\alpha$-D-glucopyranoside;

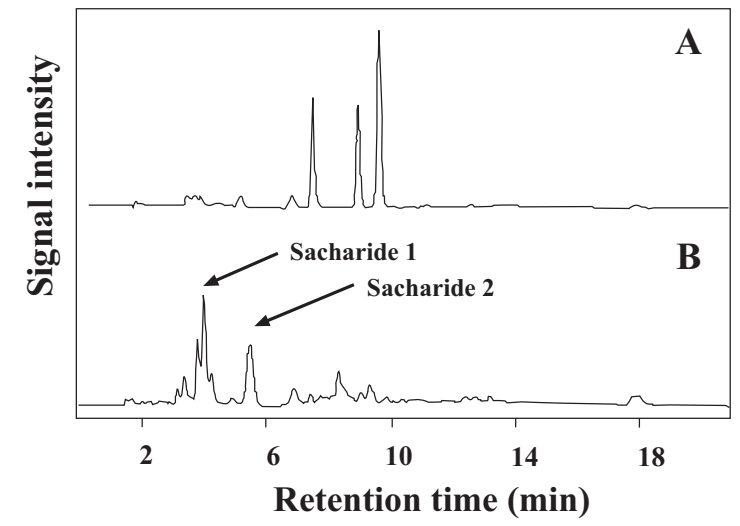

Fig. (5). High performance liquid chromatogram of fermentation products. Analysis of saccharides produced during fermentation was done by HPAEC.

A: plant extract was fermented for 0 days.

B: plant extract was fermented for 180 days.

$\beta$-D-galactopyranosyl-( $1 \rightarrow 1)$ - $\beta$-D-fructofuranosyl-( $2 \leftrightarrow 1)$ $-\alpha$-D-glucopyranoside. These saccharides were confirmed to be produced during fermentation.

\section{REFERENCES}

[1] Okada H, Kudoh K, Fukushi E, et al. Antioxdative activity and protective effect of fermented plant extract on ethanol-induced damage to rat gastric mucosa. J Jpn Soc Nutr Food Sci 2005; 58: 209-15.

[2] Okada H, Fukushi E, Yamamori A, et al. Structural analysis of a novel saccharide isolated from fermented beverage of plant extract. Carbohydr Res 2006; 341: 925-9.

[3] Kawazoe N, Okada H, Fukushi E, et al. Two novel oligosaccharides isolated from fermented beverage of plant extract. Carbohydr Res 2008; 343: 549-54.

[4] Yasuno S, Murata T, Kokubo K, Yamaguchi T, Kamei M. Twomode analysis by high-performance liquid chromatography of $p$ aminobenzoic ethyl ester-derivatized monosaccharides. Biosci Biotechnol Biochem 1997; 61: 1944-6.

[5] Kobayashi I, Yasuno S, Hashimoto H, et al. Analysis of positional isomers of $\alpha$-linked glucooligosaccharides by $p$-aminobenzoic ethyl ester-conversion method. J Appl Glycosci 2002; 49: 461-8.

[6] Rocklin RD, Pohl CA. Determination of carbohydrate by anion exchange chromatography with pulse amperomeric detection. J Liq Chromatogr 1983; 6: 1577-90.

[7] Johnson DC. Carbohydrate detection gains potential. Nature 1986; 321: 451-2.

[8] Shiomi N, Onodera S, Chatterton NJ, Harrison PA. Separation of fructooligosaccharide isomers by anion-exchange chromatography. Agric Biol Chem 1991; 55: 1427-28.

[9] Okada H, Fukushi E, Onodera S, et al. Synthesis and structural analysis of five novel oligosaccharides prepared by glucosyltransfer from $\beta$-D-glucose 1-phosphate to isokestose and nystose using 
Thermoanaerobacter brockii kojibiose phosphorylase. Carbohydr Res 2003; 338: 879-85.

[10] Hakomori S. A rapid permethylation of glycolipid and polysaccharide catalyzed by methylsulfinyl carbanion in dimethylsulfoxide. J Biochem 1964; 55: 205-8.

[11] Brereton I, Crozier S, Field J, Doddrell DM. Quadrature detection in $F_{1}$ induced by pulsed field gradients. J Magn Reson 1991; 93: 54-62.

[12] Kienlin M, Moonen CW, Toorn A, Zijl PM. Rapid recording of solvent-suppressed 2D COSY spectra with inherent quadrature detection using pulsed field gradients. J Magn Reson 1991; 93: 423-9.

[13] Li Y-C, Montelione GT. Solvent Saturation-Transfer Effects in Pulsed-Field-Gradient Heteronuclear Single-Quantum-Coherence (PFG-HSQC) Spectra of Polypeptides and Proteins. J Magn Reson 1993; B101: 315-9.

[14] Bax A, Summers MF. ${ }^{1} \mathrm{H}$ and ${ }^{13} \mathrm{C}$ assignments from sensitivityenhanced detection of heteronuclear multiple quantum NMR. J Am Chem Soc 1986; 108: 2093-4.
[15] Hurd RE, John BK. Gradient-enhanced proton-detected heteronuclear multiple-quantum coherence spectroscopy. J Magn Reson 1991; 91: 648-53.

[16] Willker W, Leibfritz D, Kerssebaum R, Bermel W. Gradient selection in inverse heteronuclear correlation spectroscopy. Magn Reson Chem 1993; 31: 287-92.

[17] Pachler KGR, Wessels PL. Selective Population Inversion (SPI). A pulsed double resonance method in FT NMR spectroscopy equivalent to INDOR. J Mag Reson 1973; 12: 337-9.

[18] Uzawa J. Yoshida S. A new selective population transfer experiment using a double pulsed field gradient spin-echo. Magn Reson Chem 2004; 42: 1046-8.

[19] Courtois JE, Ariyoshi U. Saccharose galactosides from the roots of Cucubalus baccifer (Caryophyllaceae). Study of their structure. Bull Soc Chim 1960; 42: 737-51.

[20] Pazur JH, Marsh JM, Tipton CL. Cosubstrate specificity of the transgalactosylase of Saccharomyces fragilis. J Biol Chem 1958; 233: 277-9.

Received: March 24, 2008

Revised: April 16, 2008

Accepted: April 21, 2008

(C) Kawazoe et al.; Licensee Bentham Open.

This is an open access article distributed under the terms of the Creative Commons Attribution License (http://creativecommons.org/licenses/by/2.5/), which permits unrestrictive use, distribution, and reproduction in any medium, provided the original work is properly cited. 